\title{
Das virtudes da ardência: uso e disseminação dos frutos de Capsicum nos séculos XVI e XVII
}

\author{
On the virtues of pungency: use and spread of
} Capsicum peppers in $16^{\text {th }}$ and $17^{\text {th }}$ centuries

\author{
Christian Fausto Moraes dos Santos', Fabiano Bracht', Gisele Cristina da Conceição \\ 'Universidade Estadual de Maringá. Maringá, Paraná, Brasil
}

\begin{abstract}
Resumo: A partir do século XV, observa-se, em escala global, a disseminação do cultivo, da comercialização e do uso de muitos vegetais. Apesar de a historiografia dispor de um razoável volume de estudos publicados sobre as especiarias do Oriente, bem como sobre o impacto econômico destas no Renascimento, ainda existe espaço para uma abordagem relacionada à propagação e ao uso de plantas americanas, que também se converteram em especiarias de considerável importância cultural e econômica. Entre essas plantas, as representantes do gênero Capsicum possuem destacada importância. Baseado em textos de cronistas, médicos, herbaristas e filósofos naturais dos séculos XVI e XVII, este trabalho analisa a dispersão e o cultivo de espécies de pimentos do Novo Mundo, a partir das grandes viagens marítimas iniciadas pelos portugueses no século XV.
\end{abstract}

Palavras-chave: Pimenta. Capsicum. Intercâmbios botânicos. Filosofia Natural.

Abstract: From the fifteenth century onward occurred on a global scale the spread of farming, marketing and use of many plants. Although historiography has a reasonable volume of published studies on the spices of the East, as well as on the economic impact of these products in the Renaissance, there is still space for an approach related to the spread and use of American plants, which also became culturally and economically important spices. Among these plants, the species of Capsicum genus have an outstanding importance. Based on historical sources of writers, physicians, herbalists and natural philosophers of sixteenth and seventeenth centuries, the article analyzes the spread and cultivation of pepper species from the New World, beginning with the fifteenth century Portuguese navigations.

Keywords: Pepper. Capsicum. Plant exchanges. Natural Philosophy.

SANTOS, Christian Fausto Moraes dos; BRACHT, Fabiano; CONCEIÇÃO, Gisele Cristina da. Das virtudes da ardência: uso e disseminação dos frutos de Capsicum nos séculos XVI e XVII. Boletim do Museu Paraense Emílio Goeldi. Ciências Humanas, v. 8, n. 1, p. 59-75, jan.-abr. 2013. Autor para correspondência: Christian Fausto Moraes dos Santos. Universidade Estadual de Maringá. Laboratório de História, Ciências e Ambiente. Av. Colombo, 5790. Jardim Universitário, Bloco 4, Sala 11. Maringá, PR, Brasil. CEP87020-900 (chrfausto@gmail.com).

Recebido em 27/02/2012

Aprovado em 15/02/2013

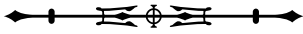




\section{INTRODUÇÃO}

A história das plantas é, por definição, a história das maneiras como o Homem relaciona-se com elas. Pois, na medida em que o Homem e suas culturas ${ }^{1}$ não estão desvinculados do meio natural, eles estão em constante relação com todas as variáveis encontradas na natureza. Deste modo, uma história dos seres vivos é também, de certa forma, uma história do Homem. Conforme notou Crosby (2011), uma cultura humana não existe sem seus animais e plantas domesticados. Observada esta questão, as indagações que surgem dizem respeito à compreensão de como aspectos importantes das culturas humanas, como, por exemplo, o comércio, a gastronomia, a medicina, a agricultura e até as linguagens, foram construídos também a partir do conhecimento adquirido pelo Homo sapiens acerca do meio natural. É neste sentido que se torna cabível a inserção de uma perspectiva que contemple a relação entre o Homem e os elementos do meio natural, do qual, entre outros, fazem parte aqueles seres vivos que classificamos atualmente como integrantes do reino vegetal.

Em todo processo de ocupação do globo pelos seres humanos, não importando se direcionarmos nosso foco para as culturas de caçadores e coletores ou para os povos que passaram pela revolução agrícola, aqueles, invariavelmente, carregaram consigo elementos da biota provenientes, no mínimo, de seu último ponto de partida (Diamond, 2008). A partir do recorte histórico deste artigo, propomo-nos estudar um dos períodos mais dinâmicos da modernidade no que se refere à disseminação de elementos bióticos do reino vegetal, bem como às transformações que, consequentemente, se processaram na estrutura do conhecimento ocidental e nos aspectos culturais de diversas sociedades.
Por volta da primeira metade do século XVI, podemos observar a ocorrência de um fenômeno histórico conectado, de maneira intrínseca, à era dos descobrimentos e que teve, entre suas características, a disseminação do cultivo, da comercialização e do consumo de uma série de elementos do reino vegetal (Ferrão, 1993). Tais elementos constituíam-se em uma grande variedade de sementes, frutos, verduras, legumes, cascas, polpas, raízes, rizomas, bulbos, tubérculos, talos, grãos, resinas, folhas, ervas e bagos de valor gastronômico, simbólico e medicinal conhecidos, neste contexto, pelo nome genérico de 'especiarias' (Ferrão, 1999, p. 44-45). O moto principal deste fenômeno, como é sabido, relaciona-se ao Oriente, especialmente às denominadas 'quatro grandes' especiarias (Nepomuceno, 2005): cravo (Syzygium aromaticum (L.) Merr. \& LM Perry), canela (Cinnamomum zeylanicum Blume), noz moscada (Myristica fragrans Houtt.) e pimenta (Piper nigrum L.).

Existe hoje um volume considerável de obras, como as de Nepomuceno (2005), Ramos (2004) e Krondl (2008), publicadas sobre a disseminação das especiarias do Oriente, que tende a abordar o impacto econômico e cultural destas plantas no Renascimento. No entanto, ainda constituem um promissor campo de estudos a disseminação e o uso de plantas originárias do Novo Mundo, as quais também se converteram em componentes de considerável importância na formação de uma série de elementos culturais e estratégicos em diversos lugares do mundo. Entre estas plantas, as solanáceas do gênero Capsicum, conhecidas popularmente como pimentos, tiveram um dos mais rápidos e amplos processos de disseminação (Santos e Bracht, 2011).

Navios que partiam dos mais diversos portos europeus, como Lisboa, Palos, La Rochelle, Dieppe, Honfleur, Londres e Amsterdã, passaram a transportar, ao

\footnotetext{
A palavra 'cultura' está, desde a sua origem, relacionada ao mundo agrícola e à vida no campo. Em latim, o termo culturae designa a agricultura e deriva do verbo colo, que significou, originalmente, 'eu cultivo'. Posteriormente, os dois termos passaram também a ser empregados para representar atividades do culto religioso ou, ainda, o ato de honrar o legado dos antepassados (Walter, 1997, p. 90; Ferreira, 1995, p. 323-324). Portanto, seja qual for o emprego escolhido para o uso da palavra 'cultura', ele se encaixa de maneira adequada ao propósito deste texto.
}

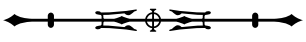


longo das novas rotas comerciais em formação, pessoas advindas de praticamente toda Europa ocidental. Galegos, portugueses, bascos, andaluzes, catalães, castelhanos, normandos, valões, flamengos, ingleses, alemães, italianos e holandeses cruzaram e esquadrinharam os oceanos em embarcações que, por diversas ocasiões, não chegavam a ter mais de 15 metros de comprimento (Bernstein, 2009).

Para garantirem a própria sobrevivência, os navegadores dos primeiros decênios da expansão comercial europeia fizeram uso de estratagemas necessários à conservação e manutenção dos hábitos e gêneros alimentícios oriundos da Europa. Este comportamento constituiu-se, em grande medida, em uma paulatina transposição, adaptação e transformação de padrões alimentares, técnicos e culturais, relativos à utilização de plantas (Crosby, 2011, p. 155-204). Tal processo de expansão desencadeou o contato de diversos povos do continente europeu não somente com outras culturas em diferentes partes do globo, mas também com uma considerável diversidade biótica, principalmente aquela encontrada no continente americano. Este conjunto de variáveis históricas e biológicas pode ser reconhecido como parte de um amplo complexo de expansão de fronteiras. Tais áreas limítrofes se configuraram tanto fisicamente, quando do contato do europeu com novos complexos naturais, quanto culturalmente, a partir dos saberes oriundos deste contato proporcionado pelo advento das grandes navegações (Quammen, 2008).

A disseminação das plantas endêmicas do Novo Mundo foi de importância crucial para a dinâmica cultural de vários povos ao redor do globo. É notório o fato de que os elementos da flora americana, principalmente aqueles já cultivados ou explorados pelo nativo, obtiveram sucesso ao acompanharem os colonizadores a regiões com características físicas diversas, como temperatura, radiação solar e pluviometria, como as encontradas no subcontinente indiano, no sul da Península Ibérica e ao norte da Europa. Sendo assim, uma análise das características biogeográficas da América pode servir como um interessante ponto de partida para a compreensão da abrangência do fenômeno que nos propusemos a analisar. Com considerável extensão longitudinal (Diamond, 2008), as Índias Ocidentais se revelaram, diante dos europeus, repletas de variedades morfoclimáticas e bióticas (Dean, 1996).

Essa diversidade, ao longo de milhares de anos, inclusive com uma dezena deles contando certamente com a presença dos seres humanos, favoreceu a evolução de uma quantidade homérica de espécies. Os europeus, subitamente, tomaram conhecimento de variedades de plantas que lhes pareceram incontáveis, as quais tiveram que ser inseridas em seu universo filosófico para que aquela 'nova' natureza pudesse ser descrita. Muitas dessas plantas possuíam, na perspectiva do europeu quinhentista, características análogas àquelas apreciadas nas especiarias orientais. Desta forma, ao final do século XV e durante a maior parte dos dois séculos seguintes, os europeus, ao percorrerem as matas e florestas americanas, buscaram nomear, descrever e classificar plantas que curassem, matassem, alimentassem e que tivessem potencial mercantil. Enfim, havia a possibilidade de se encontrar especiarias nas Índias Ocidentais (Krondl, 2008, p. 143-190).

\section{FRUTOS DE CAPSICUM: AS ESPECIARIAS DA AMÉRICA}

Uma das características físicas marcantes da floresta tropical é a considerável diversidade florística. Imaginemos o quanto isso se traduziu em uma grande confusão verde para os colonizadores quinhentistas. $\bigcirc$ que, em diversos aspectos, foi traduzido também como um sem número de oportunidades e demandas. Aqueles homens tiveram, diante de si, o desafio de descobrir, dentro do que inicialmente parecia ser um exuberante jardim do Éden, o que lhes fosse útil, proveitoso e lucrativo.

Grande parte do esforço empreendido na apreensão e sistematização da flora do Novo Mundo deu-se a partir da procura por similitudes que permitissem o encontro de equivalentes (Foucault, 2000), não apenas em relação às plantas europeias, mas também quanto às especiarias do 
Oriente. Neste aspecto, um grupo de plantas relativamente pouco estudado pela historiografia foi relevante para a construção de hábitos alimentares e para um processo mais amplo de assimilação de elementos oriundos da flora americana, bem como para sua introdução nos compêndios médicos e herbários europeus no decorrer dos séculos XVI e XVII (Debus, 2002, p. 47-50). Estamos nos referindo, especificamente, aos pimentos (Capsicum sp.) e à sua inserção no cotidiano europeu, africano e asiático. Para tal, abordaremos estas plantas americanas enquanto componentes da alimentação diária e recurso nutricional para navegantes e colonizadores do Novo Mundo.

Outro tema em nossa abordagem será o da importância do gênero Capsicum enquanto objeto de estudo de herboristas do Renascimento, sua presença na composição de símplices e mezinhas, prescritas por médicos e boticários em vários pontos do continente europeu, como terapia eficaz para várias enfermidades. Desta forma, procuraremos analisar duas questões relativas à história deste grupo de plantas, ou seja, como se deu sua dispersão e de que forma ele foi inserido no universo da Filosofia Natural do Renascimento.

Os frutos do gênero Capsicum, que ajudaram a lotar os tonéis dos navios europeus a partir do século XVI, também são conhecidos popularmente, entre outros nomes, como ardidas, dedo-de-moça, piripiri, tabasco, jalapeño, pimentão e pimenta doce. Estes pimentos, quase sempre chamados de pimentas e que não têm relação botânica próxima com a pimenta negra (Piper nigrum), estiveram entre as primeiras especiarias americanas a serem dispersas para além de seus locais de origem. Nos porões dos navios que faziam comércio no litoral da América do
Sul, junto com o pau-brasil (Caesalpinia echinata Lam.), desde o século XVI, era possível encontrar os frutos de Capsicum (Staden, 1998 [1548]). Essas plantas da família das solanáceas (Joly, 1991, p. 588) são, provavelmente, originárias (de maneira independente ${ }^{2}$ ) de diversas partes das Américas, tanto do Sul quanto Central e Antilhas.

Os registros arqueológicos mais antigos dos Capsicum foram feitos no México e datam de, aproximadamente, nove mil anos. Os pimentos também eram, possivelmente, cultivados nos Andes peruanos por volta de 2500 anos A.C. Além da ampla distribuição silvestre, o cultivo, por parte dos nativos americanos, ocorria provavelmente associado ao do milho (Zea mays L.), com o qual formava um importante complexo nutricional. Esta associação foi, aparentemente, comum aos hábitos alimentares de diversos povos précolombianos que ocuparam a grande extensão latitudinal entre o sul do atual território dos Estados Unidos e a região central da Argentina e do Chile (Barbieri e Stumpf, 2008, p. 738). Sua distribuição, à época da chegada dos primeiros europeus, compreendia, portanto, não apenas ampla dispersão latitudinal, como também uma variação de altitude, que ia do nível do mar até três mil metros ${ }^{3}$.

Atualmente, é bem difundida a informação de que o primeiro contato dos europeus com estes frutos se deu durante as viagens de Cristóvão Colombo, ainda no século XV (Ferrão, 1993, p. 110-112). A partir daí, sabe-se que sua disseminação foi rápida, sendo que podiam ser vistos e, provavelmente, cultivados desde o século XVI, na Europa, costa ocidental da África e em boa parte da Ásia (Ferrão, 1993, p. 110). Mais de uma variedade destes arbustos era, na mesma época, encontrada também em hortas e quintais na península ibérica (Monardes, 1574, p.

\footnotetext{
2 Ao que indicam os estudos citogenéticos, a domesticação não se deu em um único ponto para depois ser dispersada. Pelo contrário, é mais provável que a grande variedade de cultivares seja produto, justamente, do fato de as várias espécies terem surgido, em sua forma silvestre, dispersas pelo continente americano. Ainda hoje, subsistem espécies selvagens ou semi-domesticadas na vertente oriental da região andina e na porção sudeste do litoral brasileiro. Sobre estes dois casos, estudos morfológicos indicaram origens distintas (Barbieri e Stumpf, 2008, p. 736-737).

3 O fato de as plantas do gênero Capsicum haver se desenvolvido e evoluído sob um amplo espectro de condições climáticas e biogeográficas lhes conferiu uma grande variabilidade e resiliência. Para tal, foram determinantes os índices pluviométricos, as médias de temperatura, os tipos de solo e o tempo de incidência solar, que contribuíram para produzir diferentes variedades que puderam ser transplantadas e adaptadas relativamente bem em várias partes do globo (Ferrão, 1993; Andrew, 1999; Barbieri e Stumpf, 2008).
} 
24-25), na Alemanha (Fuchs, 1542, p. 419) e até mesmo na setentrional Inglaterra (Gerard, 1595, p. 292-293). Um dos herbaristas mais afamados do século XVI, o alemão Leonhard Fuchs, em seu "De historia stirpium commentarii insignes", de 1542, desenhou e descreveu duas variedades deste gênero, Capsicum annum e Capsicum chinese (Fuchs, 1542, p. 417-419). Não obstante a sua presença em diversas partes do globo pouco tempo depois da chegada do europeu à América, os mecanismos que envolveram sua disseminação continuam sendo tema pouco compreendido pela historiografia, e isto tem produzido alguns equívocos.

\section{DISSEMINAÇÃO, COMÉRCIO E CULTIVO NA EUROPA}

É consenso entre os estudiosos do tema que os pimentos foram disseminados e cultivados em um grande número de localidades da Europa ocidental ainda durante o século XVI (Ferrão, 1993; Andrew, 1999; Barbieri e Stumpf, 2008; Bosland, 1999, p. 7; Patiño-Rodriguez, 2002). Apesar disso, a maior parte dos historiadores não consegue ir além do mapeamento feito por Ferrão (1993). Alguma controvérsia reside, principalmente, no que se refere à disseminação dos Capsicum no norte da Europa. Neste ponto, procuraremos elencar elementos que possibilitem uma rediscussão acerca da introdução e dispersão destas solanáceas na Europa do século XVI.

Das fontes documentais referentes à América portuguesa quinhentista, vêm importantes indícios que nos permitem uma reflexão mais detida acerca dos percursos feitos pelos Capsicum desde o Novo Mundo. Algumas das mais ricas descrições sobre a presença de pimentos em navios europeus são as do alemão Hans Staden, artilheiro mercenário que esteve cativo dos índios Tupinambá no litoral sudeste da América portuguesa no final da primeira metade do século XVI. Staden relatou a presença de muitos navios franceses, que ancoravam regularmente ao longo da costa. Os franceses, que por aquela época possuíam aliança com os Tupinambá, aportavam na porção da América do Sul que cabia aos portugueses, como fora definido pelo Tratado de Tordesilhas, em busca dos mais variados produtos, trocados com indígenas por mercadorias europeias. Das naus relatadas, todas fizeram carga de pau-brasil (Caesalpinia echinata) e de outras mercadorias da terra. Entre os itens mais procurados, estavam os papagaios, diversos tipos de penas, algodão (Gossypium sp.) e grande quantidade de pimentos (Capsicum sp.) (Staden, 1998 [1548]). Em uma destas oportunidades, a estadia do navio Marie Bellete foi assim relatada por Staden: "Eles contaram que a nau francesa 'Marie Bellete', vinda de Dieppe, com a qual eu gostaria de ter navegado, fizera na terra deles um carregamento de paubrasil, 'pimenta', algodão, ornamento de penas, macacos, papagaios e outras mercadorias de que precisavam (...)" (Staden, 1998 [1548], p. 116).

O porto normando de Dieppe, assim como outros portos do norte da França, tais quais Rouen, Le Havre e Honfleur, eram, no século XVI, locais de partida e chegada de muitos navios que vinham à América (Guedes, 2002, p. 143-168). O movimento de navios bretões e normandos aportando no litoral da América portuguesa era consideravelmente intenso. Guedes (2002, p. 159) contabilizou que, num curto período no início de 1541 , de Rouen e Dieppe partiram 24 navios para a costa do Brasil. Para tal afirmação, Guedes buscou dados na obra de Charles de la Roncière, intitulada "Histoire de la Marine Française". Segundo Roncière, em uma única expedição, no ano de 1546, do porto normando de Le Havre partiram 28 embarcações com destino ao mesmo local em que aportara o navio de Dieppe descrito por Staden (Roncière, 1906, p. 303). Muitos destes navios tinham os mesmos objetivos do Marie Bellete, como a nau Catherine de Vatteville. Ela partiu do norte da França, muito provavelmente de Honfleur (Guedes, 2002, p. 143-168), e pretendia reunir "(...) uma carga de pimenta e outros bens de que precisava (...)" (Staden, 1998 [1548], p. 116).

Outro exemplo interessante é o do navio normando La Pélerine. Quando de volta à Europa, proveniente da costa de Pernambuco, foi capturado pelos portugueses em 
1531, ainda com toda sua carga (Guedes, 2002, p. 156). Na citação, segue o butim, no valor de 62.300 ducados, que caiu em mãos lusas:

(...) cinco mil quintais (cerca de 300 toneladas) de pau-brasil, ou seja, oito ducados por quintal.

300 quintais de algodão, no valor de três mil ducados, a dez ducados o quintal.

'300 quintais de grãos do país', valendo 900 ducados, a três ducados o quintal.

600 papagaios, sabendo algumas palavras em francês, valendo 3.600 ducados, a seis ducados cada.

Três mil peles de onça e outros animais, no valor de nove mil ducados, a três ducados cada pele.

Três mil ducados de ouro e mil ducados de óleos medicinais (Guedes, 2002, p. 156).

O La Pélerine foi tomado menos de vinte anos antes do período em que Hans Staden esteve na América do Sul. À época de sua captura, não são muitas as notícias do uso do termo 'pimenta' para designar os frutos de Capsicum, mas sim enquanto analogia para classificar seu efeito pungente. Como as fontes sugerem, tal associação foi construída paulatinamente, ou seja, a atribuição do nome aos frutos estava em curso no período da captura do La Pélerine. Tanto que, quando a narrativa de Staden foi publicada em 1557, o termo 'pimenta' já havia se consolidado e era claramente empregado para fazer referência aos frutos de Capsicum:

(...) Asseguraram saber muito bem que os franceses eram inimigos dos portugueses, assim como eles próprios o eram. Afirmaram que os franceses vinham todo ano com naus, trazendo facas, machados, espelhos, pentes e tesouras, e recebendo em troca pau-brasil, algodão e outras coisas, como penas de pássaros e pimenta. Por isso eram bons amigos (...) (Staden, 1998 [1548], p. 67).

Em outra passagem, é sugerida a ideia de que os pimentos seriam o alvo principal de uma expedição: "Já contei sobre o francês Caruatá-uará. Ele tinha ido embora com seus seguidores, selvagens aliados dos franceses, com a intenção de ajuntar mercadorias de comércio dos selvagens, sobretudo pimenta e um determinado tipo de penas" (Staden, 1998 [1548], p. 84).

Não muito tempo depois, outro navio ancorou, desta vez provavelmente na baía de Guanabara:

\begin{abstract}
Cerca de oito dias antes da expedição de guerra, uma nau francesa havia ancorado numa enseada localizada a aproximadamente oito milhas de Ubatuba. Em português, a enseada chama-se Rio de Janeiro; os selvagens dão-lhe o nome de Niterói. Os franceses cuidavam de embarcar um carregamento de pau-brasil naquele local. Também foram com um barco a Ubatuba, a fim de fazer comércio, para obter dos selvagens pimenta, macacos e papagaios. Um deles, que entendia a língua dos selvagens, saíra do barco e estava em terra, negociando com estes. Chamava-se Jakob, e foi a ele que pedi para me levar à nau. Contudo, os meus senhores não pretendiam deixar-me partir tão facilmente, querendo obter muitas mercadorias em troca (...) (Staden, 1998 [1548], p. 98).
\end{abstract}

Dificilmente poderíamos atribuir caráter de coincidência ao fato de estarem presentes na lista de carga do La Pélerine e nos relatos sobre o Marie Bellete e outros navios, pau-brasil, algodão (Gossypium sp.), peles e penas. Tais mercadorias, no século XVI, eram traficadas em razoável quantidade para a Europa. No entanto, os pimentos, também comuns a todas as descrições de Staden, curiosamente, estão ausentes da lista de matalotagem do La Pélerine. É neste ponto que o cruzamento dos relatos nos sugere, com fortes indícios, que os '300 quintais de grãos do país', constantes da lista do navio capturado pelos portugueses em 1531, eram, se não na sua totalidade, pelo menos na maior parte, os diminutos frutos de Capsicum já parcialmente desidratados. É muito provável terem sido designados como 'grãos do país' devido à dimensão reduzida dos frutos (de mais de uma variedade) de Capsicum chinense Jacq. e/ou Capsicum baccatum L. Lembremo-nos que as duas espécies são endêmicas do Brasil, sendo os frutos de $C$. chinense de 
formato arredondado, com um centímetro de diâmetro, em média, enquanto uma das variedades de C. baccatum, conhecida popularmente pelo nome de cumari, produz os menores frutos do gênero, arredondados, ovalados ou elipsoides (Lorenzi e Abreu Matos, 2008, p. 500).

Deste modo, ponderamos que a hipótese de se considerar os ditos 'grãos do país' como bagas de Capsicum desidratadas confere maior coerência à análise das fontes do que à ideia apresentada por Johnson (1992, p. 215216), segundo a qual o La Pélerine estava transportando, por ocasião de sua captura, 300 quintais de sementes de algodão da espécie Gossypium brasiliense Macfad. $\bigcirc$ mesmo ocorre em dois textos que podem ser considerados como fundamentais para o estudo do episódio do La Pélerine. Um deles, de Charles de la Roncière, apresentou a carga deste navio francês da seguinte maneira:

(...) bois de Brésil, des quintaux de coton, du minerai d'or, desgraines, despeaux de léopards et six cents perroquets, sachant quielques mots de français, de ces perroquets et de ces sagouins qui s'ébattaient déjà dans la villa de 1'amiral de France à Aspremont (Roncière, 1906, p. 281).

O outro é o de Guénin (1901, p. 44), que descreveu a carga confiscada pelos portugueses como sendo de:

5.000 quintaux de bois du Brésil, dont le cours était alors en France de 8 ducats le quintal, ce qui représentait une valeur de 40.000 ducats;

300 quintaux de coton d'une valeur de 900 ducats, à 3 ducats par quintal;

Autant de graines de ce pays d'une valeur de 900 ducats, à 3 ducats par quintal;

600 perroquets, sachant déjà quelques mots de français, d'une valeur de 3.600 ducats, à 6 ducats l'un;

3.000 peaux de léopards et d'autres animaux, d'une valeur de 9.000 ducats, à 3 ducats par peau;

Du minerai d'or pour 3.000 ducats, et des huiles médicinales pour 1.000 ducats;

Le tout s'élevant au chiffre de 62.300 ducats.
Neste excerto, baseado, segundo o autor, nos documentos originais dos arquivos franceses e portugueses, não há, assim como na lista de Guedes e tampouco na obra de Roncière, indicação clara sobre a natureza dos '300 quintais de grãos do país' que estavam nos porões do La Pélerine. No entanto, os diminutos frutos de Capsicum podem ser desidratados ao ar livre, isentos da ação de fungos, mesmo quando submetidos a níveis altamente variáveis de umidade e temperatura, sem que percam a maior parte de suas propriedades condimentares e nutricionais devido à ação de várias substâncias conservativas, presentes na composição dos óleos essenciais (Vega-Gálvez et al., 2007, p. 44; Barbieri e Stumpf, 2008, p. 732; Tunde-Akintunde et al., 2004, p. 439-442; Tunde-Akintunde, 2011, p. 2139-2145; Arslan e Özcan, 2010, p. 504-513).Ou seja, quando os frutos de Capsicum recolhidos pelos indígenas, como os mencionados no relato de Staden, chegavam à Europa, estes estavam desidratados, podendo ser confundidos com grãos devido à pequena dimensão e compactação.

Também existem evidências de que a palavra francesa graine foi utilizada, no século XVI, para designar frutos de Capsicum. Assim o fez André Thévet em 1557, segundo o qual os produtos adquiridos dos indígenas pelos cristãos consistiam de:

\begin{abstract}
(...) monnes, bois de bresil, perrouquets, coton, en chãge d'autres choses, comme nous avons dit. Il s'apporte aussi de la certaine espice qui est la graine d'une herbe ou arbrisseau de la hauter de trois ou quatre pieds. Le fruit ressemble à une fraise de ce pays, tant en coleur que autrement. Quand il est meur il se trouve dedans une petite semence comme fenoil. Nos marchans Chrestiens se charget de cette maniere d'espice, non toutefois si bonne que la maniguette qui croist em la coste de l'Ethiopie, et en la Guinée: aussi n'est elle à comparer à celle de Calicut, ou de Taprobane (Thévet, 1878, p. 241-242).
\end{abstract}

Somado a isso, há o fato de as sementes de algodão, que segundo Johnson (1992) eram transportadas em larga escala para a Europa, não constarem nos relatos de 
Staden, Léry, Sousa e Gândavo. Tampouco estão presentes nos herbários de maior circulação do século XVI. Ao contrário, os pimentos, além de aparecerem em profusão nos relatos dos cronistas, também constam das obras de herbaristas e outros eruditos, como Monardes e Cristóvam da Costa. Assim, além de seu translado comprovado, temos diversas indicações de seu cultivo na Europa. Essas são evidências suficientes para acreditarmos que os ditos grãos transportados pelo La Pélerine sejam, na verdade, pimentos desidratados.

Algo de conclusivo também pode ser extraído deste cruzamento de fontes documentais que acabamos de fazer, principalmente no que diz respeito ao volume aproximado das cargas descritas por Staden. Ao tomarmos como referência os dados fornecidos por Guedes (2002, p. 156), os '300 quintais' do La Pélerine perfaziam, no século XVI, aproximadamente dezoito toneladas de pequenos frutos ressecados. Talvez esta fosse a média do volume de carga citado por Staden ${ }^{4}$.

Temos, portanto, dados suficientes para supor que, mesmo que a disseminação destas plantas na Península Ibérica e bacia do Mediterrâneo tenha se dado, majoritariamente, pelas mãos de portugueses e espanhóis (Andrew, 1999, p. 31), foram os franceses os responsáveis por boa parte da disseminação inicial dos pimentos no norte da Europa. Nossa conclusão refuta, portanto, uma ideia relativamente bem aceita entre os historiadores dedicados ao estudo da disseminação dos Capsicum, segundo a qual os pimentos descritos e desenhados por Fuchs e Besler teriam chegado ao norte da Europa via Península Ibérica até Antuérpia, ou num caminho mais longo e menos provável, a partir de sua introdução no Oriente, via Istambul, Veneza, Gênova e então além dos Alpes (Andrew, 1999, p. 30-31). Discordamos de tal hipótese devido ao fato de que, como procuraremos mostrar, a introdução dos pimentos no Oriente foi simultânea - e não anterior - à sua chegada ao norte da Europa.

A costa normanda, no século XVI, estava interligada por rotas marítimas e terrestres a diversos pontos do norte da Europa, sendo provável que fosse visitada regularmente por navios da Liga Hanseática (Guedes, 2002, p. 143-168). Deste ponto, para a difusão dos pimentos no interior do continente europeu, o caminho não foi longo. Lembremo-nos que os Capsicum se reproduzem por meio de sementes, as quais, por sua vez, podem ser obtidas a partir de frutos secos. Ao que parece, estes arbustos tropicais não têm qualquer dificuldade em se aclimatar e adotar um ciclo reprodutivo anual nos domínios morfoclimáticos temperados (Barbieri e Stumpf, 2008, p. 730). Tais dados nos fornecem um substrato, no mínimo razoável, para supormos que herbaristas como Fuchs, na Alemanha, tiveram contato com exemplares vivos destas solanáceas para elaborarem seus estudos. Esta ideia torna-se ainda mais plausível se levarmos em conta uma das características fundamentais da confecção de herbários durante o Renascimento. Afinal, a prolífica origem que comungam artista e botânico no início do século XVI já há muito reconhecia a necessidade da utilização de espécimes vivos para o debuxo de gravuras e desenhos de plantas (Debus, 2002, p. 42).

Essa constatação pode ser encontrada no livro de John Gerard, herbarista inglês que afirmou ter feito estudos a partir de duas variedades de pimentos já presentes nas hortas inglesas em 1595 (Gerard, 1595, p. 292-293). É certo, no entanto, que mesmo havendo a possibilidade de adaptação dos Capsicum ao clima mais frio da Europa setentrional, esta não se deu sem algum tipo de alteração no ciclo de vida e nas características morfológicas das plantas. Algumas variedades, segundo Gabriel Soares de Sousa (1971 [1587]), em seu ambiente originário (nos trópicos), eram de considerável estatura, chegando a formar

\footnotetext{
4 Quintal é um termo de origem árabe, que designou uma medida de peso muito usada em Portugal da Idade Média até a adoção do sistema métrico decimal no século XIX. Estudos recentes indicam que o quintal português da primeira metade do século XVI correspondia a atuais 58,752 kg (Lopes, 2005, p. 48).
}

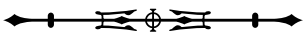


"árvores meãs" (Sousa, 1971, p. 186). Na Península Ibérica, podemos afirmar, a partir das informações publicadas em 1574 pelo médico de Sevilha, Nicolas Bautista Monardes, que os pimentos se encontravam profusamente difundidos. O relato de Monardes dá conta de que, na Andaluzia, tais plantas chegavam mesmo a ter o tamanho de árvores (Monardes, 1574, p. 24). Não sabemos precisamente a que árvores os pimentos foram comparados nestes relatos; no entanto, é certo que ambas as informações se referem a plantas relativamente grandes. Ao compararmos estes dados com as descrições de Gerard (1595), constatamos que as sementes que originaram as pimenteiras Capsicum cultivadas na Inglaterra eram provenientes da Espanha de Monardes. Os 'pimentos britânicos' atingiram, no máximo, um pé de altura ${ }^{5}$ (Gerard, 1595, p. 292-293).

É notória, portanto, a considerável diferença de tamanho entre as plantas cultivadas com relativo sucesso na Península Ibérica e aquelas transplantadas, as quais, apesar de algumas dificuldades iniciais no processo de aclimatação, se adaptaram razoavelmente bem no norte europeu ${ }^{6}$. Ao que parece, os europeus de terras mais temperadas, como as ilhas britânicas, já dominavam as técnicas necessárias para o cultivo de Capsicum. Gerard descreveu que as sementes deveriam ser plantadas primeiro em uma esteira contendo esterco morno de cavalo, e ser transferidas, posteriormente, para um pequeno vaso, mas não antes de as mudas contarem com duas ou três folhas (Gerard, 1595, p. 292-293).

A questão climática, no processo de adaptação dos pimentos à Europa, foi um ponto delicado, sobre o qual se debruçaram indivíduos pelos mais variados motivos. Em uma compilação de escritos de outros eruditos, traduzidos para o latim e comentados por Charles L'Ecluse, publicada em 1605, há um relato bem conhecido sobre a grande presença de pimentos em Lisboa e arredores. Esta descrição contém uma interessante observação sobre a influência do clima no desenvolvimento das plantas, pois, em Portugal, "Flores et Fructum prosert toto Autumno, et in calidioribus regionibus etiam Hieme" [Flores e frutos prosperam por todo o outono, e nas regiões mais quentes também no inverno] (L'Ecluse, 1605, p. 341). A compreensão do mecanismo climático foi, deste modo, imprescindível ao sucesso da difusão dos pimentos; de fato, não foi por acaso que, ao final do século XVI, a adaptação de Capsicum à Europa se encontrava muito bem consolidada.

Ao que parece, diversas variedades dos diminutos e coloridos frutos eram, há muito, apreciadas pelos europeus enquanto ingredientes culinários. Este hábito foi comum na América, onde uma variedade era especialmente preferida entre os colonizadores. Seca e moída, misturada ao sal, dentro do saleiro, a 'cuiém' servia para o tempero dos mais variados alimentos (Sousa, 1971, p. 186) ${ }^{7}$. Na Europa, Monardes, em sua obra publicada em Sevilha no ano de 1574, relatou que, na Andaluzia e em outras partes da Espanha, os pimentos eram utilizados como condimento em guisados e conservas de vários tipos (Monardes, 1574, p. 25). Monardes comparou o pimento americano com a pimenta-do-reino asiática, chegando a dizer que as pimientas das Índias Ocidentais (ou seja, do Novo Mundo) eram mais aromáticas e de melhor gosto que a pimienta do reino das

5 No original de John Gerard, aparece a palavra foote, que corresponde à unidade de medida utilizada na Inglaterra no século XVI, cuja versão moderna, no sistema imperial de medidas, é o 'pé' (foot), o que equivalia a aproximadamente 33,4 cm (Zupko, 1977).

6 O fato de as duas plantas desenhadas e descritas por Gerard contarem com flores e frutos pode ser tomado como um indicador seguro de que elas prosperaram, completando, assim, seu ciclo de desenvolvimento (Gerard, 1595, p. 292).

7 Ver, por exemplo, o relato de Sousa (1971, p. 186): "À sombra destes legumes, e na sua vizinhança, podemos ajuntar quantas castas de pimenta há na Bahia, segundo nossa notícia; e digamos logo da que chamam cuiém, que são tamanhas como cerejas, as quais se comem em verdes, e, depois de maduras, cozidas inteiras com o pescado e com os legumes, e de uma maneira e de outra queimam muito, e o gentio come-a inteira, misturada com a farinha. Costumam os portugueses, imitando o costume dos índios, secarem esta pimenta, e depois de estar bem seca, a pisam de mistura com o sal, ao que chamam juquiraí na qual molham o peixe e a carne, e entre os brancos se traz no saleiro, e não descontenta a ninguém. Os índios a comem misturada com a farinha, quando não têm que comer com ela. Estas pimentas fazem árvores de quatro e de cinco palmos de alto, e duram muitos anos sem se secar (...)". 
Índias Orientais, então a principal especiaria buscada no Oriente (Monardes, 1574, p. 24-25). Não admira que ele, assim como outros médicos e herbaristas, além de muitos cronistas e viajantes do século XVI que tiveram contato com a pimienta do Novo Mundo, a considerassem uma droga poderosa.

\section{A PIMIENTA DE LAS INDIAS E A MEDICINA HIPOCRÁTICO-GALÊNICA}

Os elementos advindos da flora do Novo Mundo foram, paulatinamente, incluídos no conjunto dos conhecimentos europeus relativos ao mundo natural. Entretanto, eles não foram simplesmente encaixados em um modelo explicativo e descritivo da natureza. Cada novo relato ou descrição, cada nova planta, semente ou fruto que desembarcava nos portos, nas mesas e prateleiras de boticários europeus representava, em si, um novo e particular desafio à filosofia natural, que se mantinha relativamente incólume desde o fim da Idade Média. Ora, somente da América portuguesa quinhentista, chegaram até a Europa mais de 800 descrições diferentes de plantas, que, por vezes, não conseguiam ser alocadas, de maneira satisfatória, dentro do princípio descritivo das similitudes.

Tal impacto epistemológico seria sentido por quase toda a modernidade, fazendo parte efetiva da grade de mudanças na estrutura da filosofia natural processada ao longo dos séculos XVI e XVII (Debus, 2002; Foucault, 2000). Segundo Hall (1988), a influência da filosofia natural greco-romana havia sido peremptória durante a maior parte da baixa Idade Média, e um volume considerável da herança intelectual daquele período foi construído desde, pelo menos, o século XII, a partir de traduções baseadas diretamente nos originais gregos e latinos feitas por eruditos que trabalhavam em Toledo e outros centros europeus do saber. No entanto, estas traduções tendiam a ter pouca circulação, e muito do conhecimento grego no campo dos estudos sobre a natureza permaneceu, de certa forma, esquecido. Foi apenas a partir do Renascimento que a redescoberta da língua grega na Europa Ocidental ganhou um novo impulso, e os eruditos passaram a ter contato com versões traduzidas, principalmente, do árabe de Arquimedes, Ptolomeu, Galeno, Platão, Aristóteles e Dioscórides. Esta redescoberta abriu caminho a novas perspectivas filosófico-naturais e lançou luz em problemáticas que ainda não haviam sido confrontadas, principalmente após o efeito catalisador das grandes descobertas marítimas e os novos biomas que se revelaram aos europeus (Hall, 1988, p. 24-26). Os pimentos constituíram, neste contexto, um dos inúmeros casos de inserção de novos elementos oriundos das Américas que contribuíram para a transformação da filosofia natural.

Nesse sentido, alguns homens de letras do período foram importantes correspondentes das notícias oriundas daquele novo mundo natural. $\bigcirc$ jesuíta espanhol Joseph de Acosta foi um deles. Em sua obra publicada em 1590, constatou que os pimentos estavam presentes em vários pontos da América, sendo chamados de 'aji', no Caribe; de 'uchu', no altiplano peruano; e 'chili', no México. Movido pelos princípios que regiam a classificação e descrição das plantas enquanto medicamentos durante o Renascimento, ele atestou algumas propriedades que confeririam àquelas solanáceas os predicados curativos. Acosta também alertou para o fato de que, se consumidos em demasia, os frutos de Capsicum poderiam ser de:

(...) muy ruines efectos, porque de suyu es muy cálido, y humoso y penetrativo, por donde el mucho uso de él em mozos, es prejudicial a la salud, mayormente del alma, porque provoca a sensualidade, y es cosa donosa que con ser esta experiência tan notória del fuego que tiene en sí, y que al entrar y salir dicen todos que quema (...) (Acosta, 2006, p. 199).

Do ponto de vista bioquímico, a substância pungente presente nos pimentos parece ter consideráveis efeitos sobre as atividades do sistema nervoso (Talbott e Hughes, 2008, p. 276-277), do qual faz parte o hipotálamo, responsável pela ligação desse sistema ao endócrino e também pela regulação da libido (Ganong, 1973, p. 172192). Lembremo-nos que os princípios que norteavam 
as observações de Acosta faziam parte de um complexo epistemológico em voga no Renascimento. Apesar disso, não podemos nos furtar em observar o quão interessante foi a maneira como Acosta interpretou essa reação bioquímica do corpo humano à capsaicina.

Para compreendermos a afirmação de Acosta, é necessário recorrermos à análise dos fatores que influenciaram o modo como se deu a assimilação dos pimentos ao universo do conhecimento europeu quinhentista, bem como seu uso medicinal no início da Idade Moderna. Sendo assim, é fundamental que nos perguntemos sobre a forma como se processou a inserção dos pimentos nos mecanismos de interpretação, compreensão e apreensão do mundo natural. Para tal, é preciso compreender os fatores que levaram os frutos de Capsicum a adquirirem o nome pelo qual se tornaram comumente conhecidos. Estas solanáceas foram nomeadas nos relatos portugueses, pelo menos desde a segunda metade do século XVI, como 'pimenta'; na Espanha de Monardes e Jarava, como pimienta; na Alemanha de Fuchs e Basilius Besler, como Pfeffer; e na Inglaterra de John Gerard, como pepper. A história do nome destas solanáceas no continente europeu foi, no século XIX, objeto de investigação (Ficalho, 1878). No entanto, mesmo os mais extensos e abrangentes trabalhos sobre o tema, como o de Thomaz (1999), não conseguem ir além do reconhecimento de que houve a transferência do nome dos frutos das especiarias orientais para as americanas. Poucos abordaram como se deu o empréstimo linguístico que conferiu aos Capsicum seus nomes populares.

No início da Era Moderna, de forma notória no século XVI, o princípio das similitudes teve papel essencial na construção do conhecimento ocidental sobre o mundo, tanto em suas relações físicas quanto no que concerne às questões metafísicas (Foucault, 2000, p. 33). Na concepção de realidade do Homem quinhentista, toda a natureza dialogava consigo mesma. Havia uma complexa trama de relações e semelhanças. De maneira geral, podemos compreender que, para os indivíduos ligados ao universo renascentista, no que diz respeito à natureza, o próprio mundo era concebido como uma rede de conveniências. A isto se incorpora o fato de, dentro dos parâmetros estabelecidos por esta concepção, tudo na natureza ter um propósito incorporado em sua ligação com o todo do universo. Neste contexto, a questão das analogias foi fundamental, pois o reconhecimento das semelhanças constituiu uma das formas recorrentes de assimilação, catalogação e descrição do novo.

Esta apreensão contribuiu para a descrição e ordenação do conhecimento gerado a respeito de um domínio sensível e em franca expansão. A partir da analogia, fazia-se possível a aproximação entre qualquer objeto do mundo, tendo como base seu caráter intrínseco, a partir de características ocultas e mais sutis (Foucault, 2000, p. 33). Na dinâmica das analogias havia conformidades na construção do saber acerca da physis. Desse modo, podemos observar que dois caminhos foram trilhados dentro do processo de evolução das línguas da Europa ocidental, não somente no que se refere às palavras que designam (até hoje) as pimentas asiáticas e africanas, como também os pimentos americanos. Os vernáculos de origem ibérica, pimenta ou pimienta, derivaram do latim pigmenta, que significa pigmento ou cor (Ferreira, 1995, p. 881), enquanto o italiano peppe, o inglês pepper, o alemão Pfeffer e o francês poivre derivam, segundo Ficalho (1878, p. 17), primeiro do termo grego $\pi \varepsilon ́ \pi \varepsilon \rho \imath$ e depois da palavra latina piperi, a qual, por sua vez, tem origem no étimo sânscrito pippali, usado para designar o condimento derivado de plantas nativas dos domínios tropicais da Ásia, hoje classificadas na ordem Piperalese na família Piperaceae (Joly, 1991, p. 306). É provável, portanto, que a palavra pippali se referisse a espécies que, desde a Antiguidade, estiveram entre as comercializadas com a Europa (Ficalho, 1878, p. 17). Existe, entre os estudiosos do tema, quem afirme que o termo pippali não fosse, originalmente, utilizado para designar o condimento mais conhecido dos europeus, derivado da Piper nigrum, mas sim de duas especiarias 
menos conhecidas, a pimenta longa Piper longum L. ou a Piper retrofractum Vahl (Thomaz, 1999, p. 10). De qualquer forma, o nome se refere, importando pouco a especificidade botânica, a uma ou mais especiarias de propriedades análogas.

Tanto a designação 'pimenta' quanto suas variantes - e análogas nas línguas europeias - foram empregadas para nomear produtos de origem vegetal que tinham, entre suas propriedades, e como característica marcante, a pungência. Antes das viagens de Colombo, eram amplamente conhecidas e utilizadas na Europa ocidental diversas especiarias de origem asiática e africana. Deste modo, entre os condimentos originários da família das Piperáceas, o mais largamente difundido era o obtido a partir da moagem dos frutos maduros da espécie P. nigrum (Joly, 1991, p. 308), conhecido, desde a Antiguidade, como pimenta negra ou simplesmente pimenta (Ferrão, 1993, p. 210-211). Esta especiaria era de grande importância não apenas econômica, mas também em vários aspectos relacionados ao uso como condimento e medicamento. Diversos autores corroboram a ideia de que a busca pela pimenta foi um dos principais fatores que impulsionaram o advento das grandes navegações, desde o longo périplo africano levado a cabo pelos portugueses, passando pelas viagens de Colombo sob as bandeiras unificadas de Castela e Aragão, até as penosas viagens à Índia pela rota do Atlântico.

O uso da pimenta (Piper nigrum) como medicamento era comum e não eram raros os registros desse uso em tratados e compêndios de medicina de ampla circulação na Europa, sendo tais obras norteadas pelos princípios da medicina hipocrático-galênica. De acordo com esta concepção, em vez de tratar a doença diretamente, o médico deveria proceder de forma a restabelecer o equilíbrio humoral do paciente. Essa prática era baseada no entendimento segundo o qual as enfermidades eram causadas pelo desequilíbrio de um dos quatro humores corporais, como seja o sangue, a fleuma, a bílis negra e a bílis amarela (Gately, 2001, p. 39-40).
Segundo os princípios galênicos, os humores podiam ser afetados por vários fatores, entre os quais estavam incluídos a dieta (Debus, 2002, p. 14; Gately, 2001, p. 39-40). Nesse sentido, as teorias humorais preconizavam que a cura para determinada doença poderia ser alcançada a partir da ingestão de algum alimento, isto é, da mezinha que tivesse propriedades contrárias àquelas do humor afetado. Ou seja, para o excesso de fleuma, que seria fria e úmida, o tratamento era feito a partir de medicamentos de caráter ou compleição quente. Para sanar o desequilíbrio da bile amarela, quente e seca, o tratamento consistia em ministrar ao doente medicamentos frios e úmidos. $\bigcirc$ mesmo raciocínio era aplicado à bílis negra, fria e seca, e ao sangue, quente e úmido. Compreendia-se que, da mesma forma que podiam curar, equilibrando os humores, os alimentos também podiam causar enfermidades se ingeridos de forma equivocada (Dias, 1999, p. 92-93; Mutarelli, 2006, p. 15; Goodman, 2005, p. 39).

No caso da pimenta (Piper nigrum), sua compleição quente era muito utilizada, no Renascimento, como medicamento. Diversas são as fontes documentais nas quais podemos encontrar referências a este princípio. Um número razoável de trabalhos de médicos, cirurgiões e herbaristas publicados até o final do século XVII contribuiu para a disseminação do conhecimento sobre as propriedades e o uso daqueles diminutos frutos arredondados e negros vindos da Ásia. Ao final do século $\mathrm{XV}$, portanto depois da construção do engenho gráfico de Johannes Gutenberg (Papavero et al., 1995, p. 2126), teve considerável circulação um livro de autoria de Johannes von Cuba, publicado em Estrasburgo em 1497. A obra trazia uma série de informações a respeito dos usos medicinais da espécie (Cuba, 1497, p. 354). Já no século seguinte, as autoridades em relação aos estudos das benesses oriundas da pimenta do reino eram os portugueses Garcia da Orta e Cristóvam da Costa, o francês Charles L'Ecluse, o andaluz Nicolás Monardes e o alemão Leonhardt Fuchs. Este conhecimento continuou a ser difundido no século XVII, pois os frutos de Piper 
nigrum tiveram suas propriedades curativas descritas na Alemanha, provavelmente em Nuremberg, por Basilius Besler (1640). Nestes compêndios, é possível constatar que, no âmbito dos princípios hipocrático-galênicos, os grãos de pimenta negra eram descritos como sendo de compleição quente. Exemplo de tal princípio pode ser encontrado nos escritos do médico e cirurgião Cristóvam da Costa, traduzidos e publicados diversas vezes nos séculos XVI e XVII. Podemos destacar aqui a publicação editada em Burgos no ano de 1568, na qual a pimenta foi descrita como um símplice de compleição quente, capaz de combater toda uma série de enfermidades frias e úmidas (Costa, 1568, p. 20-21). Garcia da Orta, que viveu por vários anos em Goa, na Índia, então sob controle da Coroa portuguesa, afirmou categoricamente que a pimenta (Piper nigrum) tinha compleição quente:

E com isto faço fim aos ditos àsi pimenta; porque pêra dizer o pêra Da pimenta que aproveita he pratica muyto usada, e nam ha cousa nova acerqua dos índios delia, que nós não usemos. E dizerem os índios que he fria a pimenta he cousa mais pêra rir que pêra praticar; aos quaes eu digo muytas vezes que não lhe saberei provar ser o foguo quente, porque a via, por onde se avia de provar, era porque queimava (Orta, 1895, p. 249).

Nesse mesmo colóquio, ao ser indagado por seu interlocutor sobre o que diziam os físicos do rei de Cochim $^{8}$ acerca das propriedades da pimenta, o médico respondeu que eles, como os portugueses, a consideravam quente em terceiro grau. É interessante, neste ponto, notar a postura de Orta. Em seus escritos, a força e a autoridade dos Idola Theatri, aos quais, mais tarde, iria se referir Francis Bacon em sua "Instauratio Magna” de 1620 (Papavero et al., 1995, p. 236), fossem eles os nativos indianos ou até mesmo Dioscórides e
Galeno, sucumbiram ao senso empírico e investigativo deste filósofo e médico português (Debus, 2002, p. 48). A compleição quente da pimenta oriental também era conhecida na Inglaterra, onde, em 1595, o cirurgião John Gerard afirmou que, segundo físicos árabes e persas, a compleição da pimenta também era quente em terceiro grau (Gerard, 1595, p. 1356).

A descrição da 'temperatura' atribuída à pimenta asiática, muito provavelmente, era derivada da combinação entre o gosto salgado ou amargo e a sensação de ardência (Dias, 1999, p. 92-93), ou antes, da pungência provocada nas mucosas pelas substâncias piperina, piperilina e piperloeinas $\mathrm{A}$ e $\mathrm{B}$, principais componentes do óleo essencial (2,6\% sobre o peso total, segundo análise fitoquímica) e responsáveis por seu sabor picante (Lorenzi e Abreu Matos, 2008, p. 421). Pode-se conjecturar, com alguma segurança, que a analogia básica que liga a ardência nas mucosas à descrição da 'temperatura' da pimenta é com o fogo. Esta sensação, ao ser interpretada a partir dos princípios galênicos, conferia aos alimentos ardidos um rol específico de predicados no que se refere ao combate dos desequilíbrios humorais. É justamente neste ponto que a operação classificatória baseada no princípio das similitudes (Foucault, 2000, p. 37) compôs, dentro da estrutura do conhecimento da Europa renascentista, a aproximação analógico/simpática entre as pimentas advindas do Oriente e os frutos ardidos originários da América recém-descoberta. Apesar de sua ampla variedade morfológica, os frutos do gênero Capsicum apresentam, todos, numerosas sementes presas a uma placenta central. Análises fitoquímicas nos permitem afirmar que estas sementes contêm, na composição de seus óleos essenciais, expressivas

\footnotetext{
8 Grande mercado de pimenta (Piper nigrum) durante o período pré-colonial, a fortaleza de Cochim, localizada na costa do Malabar, ao sul do subcontinente indiano, foi a primeira possessão colonial europeia na Índia. Esteve sob o controle português de 1503 a 1663 , quando foi conquistada pelos holandeses. Durante este período, Cochim foi o maior porto de saída de especiarias (para a Europa) da Índia. Foi também o local de concentração da segunda maior comunidade portuguesa no Oriente, perdendo apenas para Goa (Boxer, 2002; Bethencourt e Curto, 2010).
}

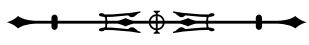


quantidades de capsaicina (que, no caso de algumas variedades de Capsicum frutescens L., é da ordem de 32 a 38\% sobre o peso total), diidrocapsacina e outros capsaicinóides (Lorenzi e Abreu Matos, 2008, p. 499500). Estes compostos são responsáveis pela sensação de queimação característica, provocada nas mucosas pela ingestão dos pimentos (Talbott e Hughes, 2008, p. 276-277). Ora, dentro da estrutura de percepção do mundo sensível característica aos europeus do século $\mathrm{XVI}$, as similitudes que aproximaram os frutos negros da pimenta asiática com as plantas Capsicum americanas foram dadas pela ardência.

Deste modo, a propriedade pungente dos pimentos não passou despercebida dos estudiosos europeus do Renascimento. Fuchs (1542, p. 417 419) os relatou como quentes. Monardes (1574, p. 24-25) foi além e disse que a "pimienta de las Indias [era] conoscida en toda España (...) [e que] calienta y conforta (...)". John Gerard (1595, p. 293) classificou a espécie de frutos longos, com a qual teve contato na Inglaterra, como quente em quarto grau. Constitui, portanto, fato compreensível que, dentro da estrutura de saber propalada durante o Renascimento, os frutos do gênero Capsicum fossem designados pelo mesmo termo utilizado para nomear a já muito conhecida pimenta asiática. Tal operação, no entanto, não se restringiu à esfera linguística e se deu, antes, a partir do estabelecimento de uma correlação não apenas entre palavras e objetos, mas em relação aos próprios objetos. Para tanto, a fusão do nome antigo à planta nova deu-se pela "comunicação de conceitos" e pela "transferência de modelos", dentro do complexo da cultura europeia, entre as pimentas e os pimentos, ou ainda entre o Oriente e o Ocidente (Rossi, 2004, p. 12-17).

A partir do reconhecimento dos mecanismos pelos quais se deram estas operações analógicas, chegamos à compreensão de que a comunicação de conceitos, sobre a qual escreveu Rossi (2004), se estendia também ao conjunto de princípios que norteava a construção do saber médico e, neste ponto, a compleição quente dos pimentos se interligava com outros elementos próprios do paradigma hipocrático-galênico. É desta forma que podemos voltar nossas atenções para a já referida afirmação de Acosta (2006, p. 199), de que os frutos de Capsicum seriam de "muy ruines efectos (...) [porque] provoca a sensualidade, y es cosa donosa (...)". De fato, os jesuítas notabilizaram-se não somente por estarem sempre preocupados com o aperfeiçoamento da moral e a salvação das almas de seu rebanho, mas também por serem dedicados estudiosos dos preceitos de Hipócrates e Galeno.

Sendo assim, a ingestão, principalmente pelos mais jovens, de um alimento/medicamento que, como os pimentos, possuía compleição quente configuravase num grande perigo. Os desequilíbrios humorais provocados pela compleição quente dos pimentos estavam associados ao ímpeto, à cólera e às paixões, características do corpo, em prejuízo das moderadas características da alma (Mutarelli, 2006, p. 14-19). Ademais, seguindo a trilha das operações analógicas, podemos lembrar que, ao tempo do rei D. Manoel, o princípio quente era indicado como um eficiente estimulante sexual (Dias, 1999, p. 94). Neste ponto, é importante compreender que o desequilíbrio humoral não só definia um estado insalubre do ponto de vista fisiológico, mas também as alterações de humor no sentido comportamental (Goodman, 2005, p. 39). Tal concepção associava cada um dos quatro fluídos que compunham o corpo a um elemento do Cosmos e à sua 'temperatura' correspondente: o sangue, quente e úmido, era associado ao Ar, a fleuma fria e úmida compartilhava da compleição da Água, conquanto que a bile negra, fria, correspondia-se com a Terra e a bile amarela, ardente, era entendida em associação com o Fogo. Por sua vez, um temperamento sanguíneo tinha a predominância do humor correspondente, o fleumático idem, o melancólico era influenciado pela bile negra e o colérico, pela bile amarela (Mutarelli, 2006, p. 16). Quanto aos pimentos, verificamos que médicos e 
herbaristas do século XVI os consideraram 'ardentes' e 'biliosos' (Monardes, 1574, p. 24-25; Fuchs, 1542, p. 417-419; Gerard, 1595, p. 292-293). Esta propriedade, dentro da epistême galênica, estava associada à cólera e também correspondia aos estímulos dos órgãos do baixo ventre, responsáveis pela libido e pelos estímulos sexuais (Foucault, 1985, p. 113).

\section{CONSIDERAÇÕES FINAIS}

Mesmo que a Europa tenha sido o centro nevrálgico do sistema mercantil, a ideia de que as outras partes do mundo participaram de sua construção de maneira apenas secundária é, no mínimo, superficial. Assim como é dado o fato de que partiram da Europa muitos dos elementos que, juntos, ajudaram a consolidá-lo, não haveria tal sistema se não tivessem saído, principalmente da Ásia e da América, componentes naturais mais do que essenciais a esta construção. Não há como conceber o período das grandes navegações sem incluirmos as variáveis históricas geradas pelas floras americana, africana e asiática, muito menos sem reconhecermos a importância dos usos, costumes e conhecimentos detidos pelos povos que as apresentaram aos colonizadores europeus.

A história da dispersão das plantas americanas pelo mundo, acompanhando o processo que deu, às nações europeias, a primazia sobre as rotas marítimas do globo, é uma história de grande capacidade de adaptação e domínio técnico. Isto se deu, na maioria das vezes, graças a um processo de antropização que superou a variabilidade climática e físico-química do solo. No entanto, esta dispersão não pode ser considerada enquanto fato isolado, ou seja, como produto apenas das relações mercantis, ou mesmo exclusiva da Idade Moderna. O mesmo padrão de dispersão biótica apontado por Diamond (2008), ao longo dos eixos lesteoeste da dispersão humana, ocorrido na Antiguidade, pode ser verificado no estudo da era das navegações. Ao longo dessas faixas longitudinais (leste-oeste), a variabilidade do clima e do tempo de incidência solar é menor do que nos eixos latitudinais norte-sul. Povos que eram praticantes de vários tipos de cultivo e pecuária, como aqueles que se estabeleceram no Crescente Fértil desde o fim da última glaciação, migraram por sucessivas gerações, expandindo a área na qual se fazia uso da agricultura. A permanência do tipo de agricultura e pecuária que eles praticavam se deu, principalmente, em direção aos territórios localizados a leste e oeste de seu ponto original, no Oriente Médio (Diamond, 2008, p. 110-112). Em grande parte dos casos, isto se deveu à maior facilidade de adaptação dos sistemas agrícolas, com suas plantas e animais domesticados, à menor variabilidade climática dos eixos longitudinais. Durante os séculos seguintes à chegada do europeu na América, a expansão biótica levada a cabo pelos colonizadores continuou a seguir o padrão leste-oeste, transladando plantas originárias do Novo Mundo para domínios morfoclimáticos similares. A mandioca, levada da América portuguesa para a África, a batata-doce, da América tropical para a Oceania, e os pimentos americanos, para o subcontinente indiano (Santos e Bracht, 2011, p. 70-74), são apenas alguns exemplos deste padrão.

Tal relação reforça, como campo de pesquisa histórica, a via de mão dupla entre o Homem e os domínios morfoclimáticos com os quais ele se depara. A partir deste princípio, é possível também afirmar a existência de uma relação direta entre o Homem, o mundo natural, os consequentes desenvolvimentos de técnicas de sobrevivência, as tecnologias e seus intrínsecos aspectos culturais. Tais questões nos permitem evidenciar uma rede de experimentações, saberes, usos práticos e significados simbólicos, por vezes, calcados em necessidades cotidianas. Portanto, não é correto pensar a história do mercantilismo ou da filosofia natural renascentista sem que estejam incluídas as variantes históricas geradas pelas plantas americanas, africanas e asiáticas, e muito menos sem reconhecer a importância dos usos, costumes e conhecimentos práticos dos povos que as apresentaram aos europeus. 


\section{REFERÊNCIAS}

ACOSTA, Joseph. Historia natural y moral de las Indias. Cidade do México: Fondo de Cultura Económica, 2006.

ANDREW, Jean. The pepper trail: history and recipes around the world. Denton: University of North Texas Press, 1999.

ARSLAN, D.; ÖZCAN, M. M. Dehydration of red bell-pepper (Capsicum annuum L.): change in drying behavior, colour and antioxidant content. Food and Bioproducts Processing, v. 89, n. 4, p. 504-513, 2010.

BARBIERI, Rosa Lia; STUMPF, Elisabeth Regina Tempel. Origem e evolução de plantas cultivadas. Brasília: EMBRAPA, 2008.

BERNSTEIN, William. Uma mudança extraordinária: como o comércio revolucionou o mundo. Rio de Janeiro: Elsevier, 2009.

BESLER, Basilius. Hortus Eystettensis, sive, Diligens et accurata omnium plantarum, lorum, stirpium. Nuremberg, 1640.

BETHENCOURT, Francisco; CURTO, Diogo Ramada. Introdução. In: BETHENCOURT, Francisco; CURTO, Diogo Ramada (Orgs.). Expansão marítima portuguesa, 1400-1800. Lisboa: Edições 70, 2010. p. 1-18.

BOSLAND, Paul. The history of chile pepper. In: HANSON, Beth (Ed.). Chile peppers: hot tips and tasty picks for gardeners and gourmets. New York: Science Press, 1999. p. 7-16.

BOXER, Charles Ralph. O império marítimo português, 14151825. São Paulo: Companhia das Letras, 2002.

COSTA, Cristóvão da. Tractado de las drogas, y medicinas de las Indias Orientales, con sus plantas debuxadas al biuo por Cristoval Acosta medico y cirurjano que las vio ocularmente. Sevilha, 1568.

CROSBY, Alfred W. Imperialismo ecológico: a expansão biológica da Europa, 900-1900. São Paulo: Companhia das Letras, 2011.

CUBA, Johannes von. Hortus sanitatis, vel Tractatus de herbiset plantis, de animalibus omnibus et de lapidibus: tractatus de urinis ac earum speciebus. Estrasburgo,1497.

DEAN, Warren. A ferro e fogo: a história e a devastação da Mata Atlântica brasileira. São Paulo: Companhia das Letras, 1996.

DEBUS, Allen G. O homem e a natureza no Renascimento. Porto: Porto Editora, 2002.

DIAMOND, Jared. Armas, germes e aço: os destinos das sociedades humanas. Rio de Janeiro: Record, 2008.

DIAS, José Pedro Sousa. O odor e o sabor da farmacologia galênica. In. GUERREIRO, Inácio (Org.). A epopeia das especiarias. Lisboa: Instituto de Investigação Científica Tropical, 1999. p. 90-103.
FERRÃO, José Eduardo Mendes. Principais especiarias tropicais. In. GUERREIRO, Inácio (Org.). A epopeia das especiarias. Lisboa: Instituto de Investigação Científica Tropical, 1999. p. 42-67.

FERRÃO, José Eduardo Mendes. A aventura das plantas e os descobrimentos portugueses. Lisboa: Instituto de Investigação Científica Tropical, 1993.

FERREIRA, Antônio Gomes. Dicionário de Latim-Português. Porto: Porto Editora, 1995.

FICALHO, Francisco Manuel de. Memórias sobre a influência dos descobrimentos dos portuguezes no conhecimento das plantas: memórias sobre a malagueta. Lisboa: Tipographia da Academia, 1878.

FOUCAULT, Michel. As palavras e as coisas: uma arqueologia das ciências humanas. Tradução Salma Tannus Muchail. São Paulo: Martins Fontes, 2000.

FOUCAULT, Michel. História da sexualidade: o cuidado de si. Rio de Janeiro: Edições Graal, 1985.

FUCHS, Leonhardt. De historia stirpium commentarii insignes. Basileia: Officina Isingriniana, 1542.

GANONG, William F. Fisiologia médica. São Paulo: Atheneu Editora, 1973.

GATELY, lain. Tobacco: a cultural history of how an exotic plant seduced civilization. Nova lorque: Grove Press, 2001.

GERARD, John. The herball or general history of plants. London: John Norton Print, 1595.

GOODMAN, Jordan. Tobacco in History: the cultures of dependence. London: Taylor \& Francis e-Library, 2005.

GUEDES, Max Justo. La terre du Brésil: contrabando e conquista. In: BUENO, Eduardo (Org.). Pau Brasil. São Paulo: Axis Mundi Editora, 2002. p. 142-168.

GUÉNIN, Eugène. Ango et ses Pilotes: d'après des documents inèdits tirés des archives de France, de Portugal e d'Espagne. Paris: Librairie Maurice Prudhomme, 1901.

HALL, Alfred Rupert. A revolução na ciência: 1500-1750. Lisboa: Edições 70, 1988.

JOHNSON, Harold. Desenvolvimento e expansão da economia brasileira. In: JOHNSON, Harold; SILVA, Maria Beatriz Nizza da (Orgs.). O império luso-brasileiro, 1500-1620. Lisboa: Editora Estampa, 1992. p. 207-299.

JOLY, Aylthon Brandão. Botânica: introdução à taxonomia vegetal. São Paulo: Companhia Editora Nacional, 1991.

KRONDL, Michael. O sabor da conquista: Veneza, Lisboa e Amsterdã na rota das especiarias. Rio de Janeiro: Editora Rocco, 2008. 
L'ECLUSE, Charles. Exoticorum libri decem: quibus animalium, plantarum, aromatum alorum que peregrinorum fructum historiae describuntur. Antuérpia: Officina Plantiniana, 1605.

LOPES, Luiz Seabra. A cultura da medição em Portugal ao longo da história. Educação e Matemática, Lisboa, n. 84, p. 42-48, 2005.

LORENZI, Harry; ABREU MATOS, F. J. Plantas medicinais no Brasil: nativas e exóticas. Nova Odessa: Instituto Plantarum de Estudos da Flora, 2008.

MONARDES, Nicolas Bautista. Primera, segunda y tercera partes de la historia medicinal de las cosas que se traen de nuestras Indias Occidentales, que sirven en medicina: tratado de la piedra bezaar, y dela yerva escuerçonera. Dialogo de las grandezas del hierro, y de sus virtudes medicinales. Tratado de la nieve, y del beuer frío. Sevilha, 1574.

MUTARELLI, Sandra Regina Kuka. Os quatro temperamentos na Antroposofia de Rudolf Steiner. 2006. 150 f. Dissertação (Mestrado em História das Ciências) - Universidade de São Paulo, São Paulo, 2006

NEPOMUCENO, Rosa. O Brasil na rota das especiarias. Rio de Janeiro: José Olympio Editora, 2005.

ORTA, Garcia da. Colóquios dos simples e drogas da Índia. Lisboa: Academia Real das Ciências de Lisboa, 1895.

PAPAVERO, Nelson; LLORENTE-BOUSQUETS, Jorge; ORGANISTA-ESPINOSA, David. Historia de la Biologia Comparada: de Nicolás de Cusa a Francis Bacon. Cidade do México: Instituto Mexicano del Seguro Social, 1995.

PATIÑO-RODRIGUEZ, Victor Manuel. Historia y dispersión de los frutales nativos del Neotrópico. Cali: Centro Internacional de Agricultura Tropical, 2002.

QUAMMEN, David. O Canto do Dodô. São Paulo: Companhia das Letras, 2008.

RAMOS, Fábio Pestana. No tempo das especiarias: o império da pimenta e do açúcar. São Paulo: Contexto, 2004.

RONCIÈRE, Charles de La. Histoire de la marine française. Paris: Plon-Nourrit Editeur, 1906. v. 3.

ROSSI, Paolo. A chave universal: artes da memorização e lógica combinatória de Lúlio até Leibniz. Bauru: Editora da Universidade do Sagrado Coração, 2004.
SANTOS, Christian Fausto Moraes dos; BRACHT, Fabiano. Bemvinda ardência: as pimentas americanas viraram um sucesso mundial ainda nos séculos XVI e XVII. Revista de História da Biblioteca Nacional, n. 66, p. 70-75, mar. 2011.

SOUSA, Gabriel Soares de. Tratado descritivo do Brasil em 1587. São Paulo: EDUSP, 1971.

STADEN, Hans. A verdadeira história dos selvagens, nus e ferozes devoradores de homens, encontrados no novo mundo, a América, e desconhecidos antes e depois do nascimento de Cristo na terra De Hessen, até os últimos dois anos passados, quando o próprio Hans Staden de Homberg, em Hessen, os conheceu, e agora os traz ao conhecimento do público por meio da impressão deste livro. Rio de Janeiro: Dantes, 1998 [1548].

TALBOTT, Shawn; HUGHES, Kerry. Suplementos dietéticos: guia prático para profissionais de saúde. Rio de Janeiro: Guanabara Koogan, 2008.

THÉVET, André. Les singularitez de la France Antartique. Paris: Maison Neuve et Cie Libraires Editeurs, 1878.

THOMAZ, Luis Felipe. O nome das especiarias. In: GUERREIRO, Inácio (Org.). A epopeia das especiarias. Lisboa: Instituto de Investigação Científica Tropical, 1999. p. 8-41.

TUNDE-AKINTUNDE, T. Y. Mathematical modeling of sun and solar drying of chilli pepper. Renewable Energy, v. 36, n. 8, p. 2139-2145, 2011.

TUNDE-AKINTUNDE, T. Y.; AFOLABI, T. J.; AKINTUNDE, B. $O$. Influence of drying methods on drying of bell-pepper (Capsicum annuum). Journal of Food Engineering, v. 68, n. 4, p. 439-442, 2004.

VEGA-GÁLVEZ, A.; LEMUS-MONDACA, R.; BILBAO-SÁINZ, C.; FITO, P.; ANDRÉS, A. Effect of air drying temperature on the quality of rehydrated dried red bell pepper (var. Lamuyo). Journal of Food Engineering, v. 85, n. 1, p. 42-50, 2007.

WALTER, Henriette. A aventura das línguas no Ocidente: origem, história e geografia. São Paulo: Editora Mandarim, 1997.

ZUPKO, Ronald Edward. British weights \& measures: a history from Antiquity to the Seventeenth Century. Madison: University of Wisconsin Press, 1977. 